\title{
Laboratory Rational of Changes in the Crystal Lattice of Nickel-Titanium Endodontic Rotary Files in Autoclaving
}

\author{
Zurab Khabadze, ${ }^{1}$ Oleg Mordanov $\mathbb{D}^{2}{ }^{2}$ Mariya Balashova, ${ }^{2}$ Leonid Stolov, ${ }^{1}$ \\ Amaliya Pangratyan, ${ }^{1}$ Roza Bokova, ${ }^{1}$ Shamil Nazhmudinov, ${ }^{2}$ Shamil Solimanov, ${ }^{2}$ \\ Anastasiya Kuznetsova, ${ }^{2}$ Anzhela Adzhieva, ${ }^{2}$ and Omargadzhi Magomedov ${ }^{2}$ \\ ${ }^{1}$ Department of Therapeutic Dentistry, RUDN University, Medical Institute, Miklukho-Maklaya str. 6, Moscow 117198, Russia \\ ${ }^{2}$ Private Practice, Verknyaya Krasnoselskaya str. 19/2-105, Moscow, Russia \\ Correspondence should be addressed to Oleg Mordanov; mordanov19@gmail.com
}

Received 11 September 2019; Accepted 11 December 2019; Published 25 January 2020

Academic Editor: Andrea Scribante

Copyright (c) 2020 Zurab Khabadze et al. This is an open access article distributed under the Creative Commons Attribution License, which permits unrestricted use, distribution, and reproduction in any medium, provided the original work is properly cited.

\begin{abstract}
Objectives. The aim of this study was to investigate the changes of the crystal lattice of NiTi instruments after repeated autoclave sterilization cycles based on the results to conclude about the influence of multiple sterilization on the characteristics of ProTaper clinical use. Methods. 21 samples of ProTaper Universal rotary files were divided into 3 groups of 7 samples. After 1, 4, and 7 cycles of sterilization, the samples were observed using energy-dispersive X-ray spectroscopy (EDX), X-ray powder diffraction (XRD), and scanning electron microscopy (SEM). Results. EDS analysis confirmed that all samples were composed mainly of nickel and titanium, also Fe (presumably steel), $\mathrm{Cr}, \mathrm{Co}$, and $\mathrm{Zn}$ were found. The percentage of nickel and titanium was affected by repeated sterilization cycles. The mass fraction of $\mathrm{Fe}, \mathrm{Co}, \mathrm{Zn}$, and $\mathrm{Cr}$ decreased after 1,4 , and 7 sterilization cycles. According to the results of the second study, it was found that, with increasing autoclaving cycles, the percentage of Fe decreased. There were changes in the three obtained diffractograms, which indicated an increase in the number of the martensitic phase and a decrease in austenitic. The cutting efficiency of the ProTaper is also reduced during repeated sterilization cycles, which can be caused by the austenitic and martensitic phase displacement. Conclusion. Manufacturing features and repeated sterilization cycles increase the internal deformation in the structure of NiTi alloy, which increases the risk of fracture.
\end{abstract}

\section{Introduction}

Nickel-titanium $(\mathrm{Ni}-\mathrm{Ti})$ rotary endodontic files are widely used in dentistry due to their distinctive properties: high flexibility, shape memory effect, and superelasticity [1-4]. $\mathrm{NiTi}$ rotary endodontic instruments have enhanced the effectiveness of endodontic treatment with regard to accuracy, reduction of apical foramen transportation, and procedural time since their introduction into clinical practice nearly 3 decades ago $[5,6]$. Procedural errors associated with traditional stainless steel instruments have been minimized since the introduction of NiTi rotary instruments [7].

The ProTaper Universal (PTU) system (Dentsply Maillefer, Ballaigues, Switzerland) is a NiTi rotary system of instruments manufactured with progressive tapering over the length of the cutting blades, convex triangular cross sections, and noncutting tips. In the PTU system, the file is produced in such a way that it does not cut the ends, and its cross section is a convex triangle. The taper angle of the file is not constant. This angle increases parabolically starting from the end $[8,9]$.

$\mathrm{Ni}$-Ti files including PTU are frequently reused after sterilization by autoclaving. Autoclaving helps in minimizing the risk of crossinfection during endodontic treatment [10]. There are different reports on autoclaving effects that improve [11] or degrade [12] both the performance and physical properties of different rotary Ni-Ti systems.

The aim of this study was to investigate the changes of the crystal lattice of NiTi instruments after repeated autoclaving cycles to conclude on the impact of multiple 
sterilization on the features of clinical exploitation of ProTaper Universal.

\section{Materials and Methods}

Twenty one samples of ProTaper Universal rotary files (Dentsply Maillefer, Ballaigues, Switzerland) were selected for the study and divided into three groups:

(1) PTU F1 with 1 autoclaving cycle

(2) PTU F1 with 4 autoclaving cycles

(3) PTU F1 with 7 autoclaving cycles

Each autoclave cycle consisted of a peak temperature of $134^{\circ} \mathrm{C}$ for $26 \mathrm{~min}$, a pressure of $2 \mathrm{bar}(1.9 \mathrm{~atm}$.), and all cycles were performed with Euroklav 23 VS+ (MELAG Medizintechnik, Berlin, Germany) according to manufacturer's instructions.

The files were examined using energy-dispersive X-ray spectroscopy (EDX), X-ray powder diffraction (XRD), and scanning electron microscopy (SEM) to analyze surface imperfections and changes of the crystal lattice. Mean results were evaluated using Student's $t$-test with $p<0.05$ statistically significance.

\section{Results}

3.1. Energy-Dispersive X-Ray Spectroscopy (EDX). It was confirmed that ProTaper Universal rotary files consist of nickel $(56.2 \pm 1.2 \%)$ and titanium $(41.2 \pm 0.9 \%)$ and the material containing $\mathrm{Fe}$ (presumably steel). In addition, $\mathrm{Ch}$, $\mathrm{Co}$, and $\mathrm{Zn}$ were revealed in the samples. The mass fraction of $\mathrm{Fe}, \mathrm{Ch}, \mathrm{Co}$, and $\mathrm{Zn}$ decreases with an increase in the number of reautoclaving, followed by the disappearance of the first three listed elements (Table 1). Changes in the mass fractions of nickel and titanium were not significant $(p=0.6)$.

3.2. X-Ray Powder Diffraction (XRD). Three radiographs describing the diffraction patterns of the samples were obtained. It was found that the percentage of Fe decreased from $41 \%$ to $2 \%(p<0.01)$, and the number of $\mathrm{Ni}$ and $\mathrm{Ti}$ compensatory increased significantly $(p<0.05)$.

The main characteristics of diffractograms with increasing sterilization change are position, width, and intensity of diffraction peaks, which indicate internal changes in the crystal lattice parameters and changes in the phase composition.

High and narrow diffraction peaks in the range of $60^{\circ}-80^{\circ}$ correspond to the high-temperature austenitic B2 phase; its crystal structure is homogeneous, and there are no microstresses in it. After 4 cycles, the intensity of austenite peaks decreased, and after 7 cycles, there was a widening of the austenite diffraction reflex, which indicates a disturbance of its homogeneity, and as a consequence, a decrease in the strength of the material.

Martensitic phase in samples increased with the increase in repeated autoclaving. This is determined by five lowintensity peaks, the so-called "crown" on diffractograms (Figure 1).
TABLE 1: Change in the mass fraction of the samples after 1, 4, and 7 sterilization cycles.

\begin{tabular}{lccc}
\hline Sterilization cycle & Element & EDX, \% & XRD, \% \\
\hline \multirow{4}{*}{1} & $\mathrm{Ni}$ & 56,2 & \\
& $\mathrm{Ti}$ & 41,2 & 41 \\
& $\mathrm{Fe}, \mathrm{Ch}, \mathrm{Co}, \mathrm{Zn}$ & 2,38 & 59 \\
\hline \multirow{4}{*}{4} & $\mathrm{Ni}$ & 57,3 & \\
& $\mathrm{Ti}$ & 42,3 & 95 \\
& $\mathrm{Fe}, \mathrm{Ch}, \mathrm{Co}, \mathrm{Zn}$ & 0,321 & 5 \\
\hline \multirow{2}{*}{7} & $\mathrm{Ni}$ & 57,4 & \\
& $\mathrm{Ti}$ & 42,3 & 98 \\
& $\mathrm{Fe}, \mathrm{Ch}, \mathrm{Co}, \mathrm{Zn}$ & 0,29 & 2 \\
\hline
\end{tabular}

EDX: energy-dispersive X-ray spectroscopy; XRD: X-ray powder diffraction.

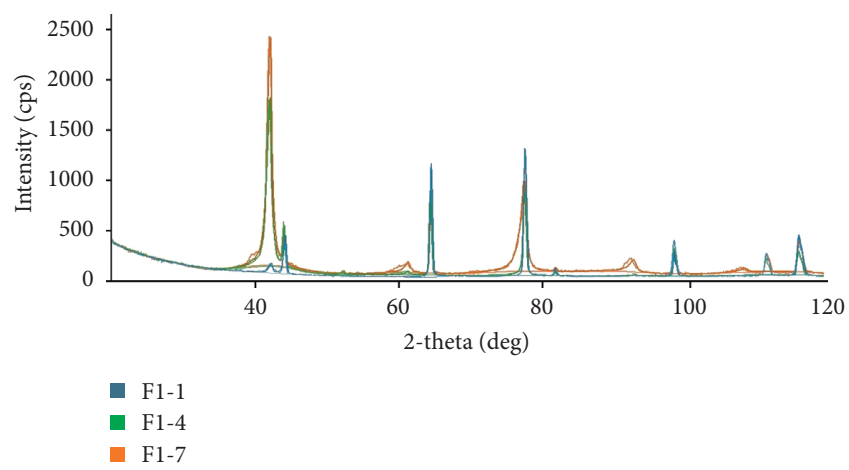

FIgURE 1: Superimposition of X-ray diffraction patterns after 1 (F1-1), 4 (F1-4), and 7 (F1-7) autoclaving cycles. 5 low-intensity peaks ("crown") are determined on the diffractogram F1-7, and it is the appearance of the martensitic phase in the visibility limit.

3.3. Scanning Electron Microscopy (SEM). Three-dimensional images of samples at different sites were obtained. The composition was typical for nitinol 55\%. Numerous milling marks were revealed on the surface of instruments. This microstructure appeared due to the features of manufacturing of NiTi instruments. Repeated autoclaving cycles do not significantly affect the morphology of the surface defects, as well as the change in the parameters of the cutting edge. SEM images of the cutting tip also showed its blunting with an increase in sterilization cycles (Figure 2).

\section{Discussion}

According to the recommendations of manufacturers, multiple cycles of disinfection and sterilization increase the risk of instrument fracture, but detailed information is absent. The effects of autoclaving NiTi files lead to the publishing of varied reports: some studies suggest that sterilization may increase NiTi torsional strength [13], whilst other investigations have reported increased susceptibility to cyclic fatigue and decreased torsional moment [11, 14]. Additional research suggests repeated NiTi autoclave sterilization negatively affects the mechanical properties and leads to premature instrument failure [15-17]. This study 


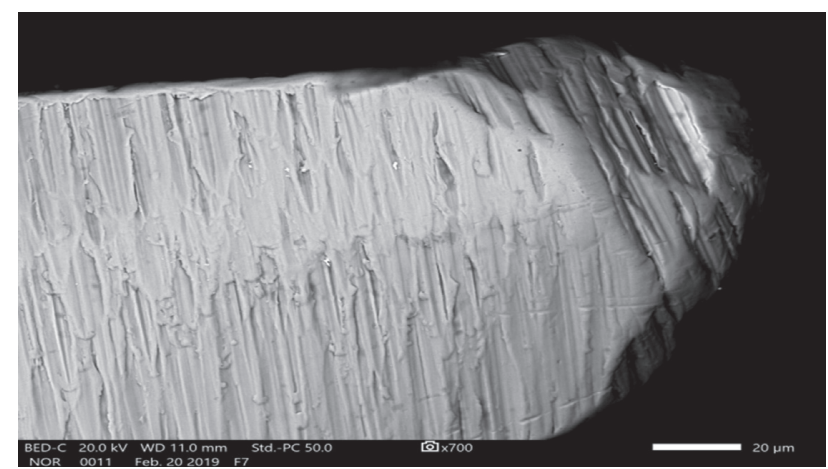

FIGURE 2: SEM image of the cutting blunting tip of the sample F1-7 after 7 autoclaving cycles. Image was taken at 700X magnification.

was aimed to investigate the crystal structure of the NiTi PTU file alloy.

The crystal structure of the NiTi alloy is characterized by reversible phase transformations during deformation due to external forces and temperature changes. On the one side, if the load exceeds of the elasticity limit of the metal austenitic phase, it begins to transform into the martensitic phase [17-19].

On the other side, transformations occurring in the process of temperature change play a significant role in the elimination of deformations in the alloy structure. It is believed that the material deformations can be almost completely eliminated if it is heated to the level of return temperature transformation $125^{\circ} \mathrm{C}$ (RTT). The initial crystal lattice is restored, and the alloy undergoes a reversible transformation from the martensitic phase to austenitic. At temperatures below $100^{\circ} \mathrm{C}$, the material is in the region of temperature transformation and begins to change its physical properties [20].

The maximum strength for the tested samples is realized in the austenitic phase. Austenitic NiTi is characterized by the stability of the structure and higher resistance to destruction, including working elastic deformations. Martensite has high hardness and strength and low plasticity; the structure is inhomogeneous, unstable and fragile. There are large internal microstresses in it. The presence of residual stresses in the martensitic phase can influence the change of crystal lattice parameters [20].

The presence of Co in the alloy helps to reduce the upper limit of transformation temperature. Thus, the temperature of the existence of a stable and deformationresistant austenitic phase is close to the treatment temperature [4].

Martensitic phase in samples increased with the increase in repeated autoclaving. The accumulation of the martensitic phase and the increase in internal microstresses lead to the fact that part of martensite cannot turn back into austenite [21]. Thus, the unstable phase accumulates.

The residual microstresses in the crystal lattice prevent reverse transformation front, which leads to a decrease in reversible deformation and consequently to an increase in residual deformation, which also reduces the strength of the material [19].
The analysis of X-ray diffraction patterns revealed the presence of displacements of X-ray reflexes of phase B2 in the region of "smaller" angles relative to their initial positions. The displacement of diffraction reflexes can be due to changes in the chemical composition and the presence of $\mathrm{B} 2$ phase deformation [17].

\section{Conclusion}

The fracture mechanism of ProTaper Universal rotary Ni-Ti files could be associated with the presence of surface defects, which are formed in the manufacturing process. These cracks are microstress concentrators in instruments. Together, manufacturing features and repeated sterilization cycles increase the internal deformation in the structure of the NiTi alloy, which increases the risk of fracture. SEM refute the assumption of using steel coating to increase the cutting efficiency.

\section{Data Availability}

The data used to support the findings of this study are included within the article.

\section{Conflicts of Interest}

The authors declare that they have no conflicts of interest.

\section{Acknowledgments}

The publication has been prepared with the funding by Peoples' Friendship University of Russia (RUDN University) and $5 / 100$ program.

\section{References}

[1] E. S. J. Pereira, I. F. C. Peixoto, A. C. D. Viana et al., "Physical and mechanical properties of a thermomechanically treated $\mathrm{NiTi}$ wire used in the manufacture of rotary endodontic instruments," International Endodontic Journal, vol. 45, no. 5, pp. 469-474, 2012.

[2] E. S. J. Pereira, R. O. Gomes, A. M. F. Leroy et al., "Mechanical behavior of M-wire and conventional NiTi wire used to manufacture rotary endodontic instruments," Dental Materials, vol. 29, no. 12, pp. e318-e324, 2013.

[3] G. Gavini, M. d. Santos, C. L. Caldeira et al., "Nickel-titanium instruments in endodontics: a concise review of the state of the art," Brazilian Oral Research, vol. 32, no. 1, p. 32, 2018.

[4] J. Bennett, K. H. Chung, H. Fong, J. Johnson, and A. J. Paranjpe, "Analysis of surface characteristics of ProTaper universal and ProTaper next instruments by scanning electron microscopy," Journal of Clinical and Experimental Dentistry, vol. 9, no. 7, pp. e879-e885, 2017.

[5] C. Poggio, A. Dagna, M. Chiesa, R. Beltrami, and S. Bianchi, "Cleaning effectiveness of three NiTi rotary instruments: a focus on biomaterial properties," Journal of Functional Biomaterials, vol. 6, no. 1, pp. 66-76, 2015.

[6] H. Walia, W. A. Brantley, and H. Gerstein, "An initial investigation of the bending and torsional properties of Nitinol root canal files," Journal of Endodontics, vol. 14, no. 7, pp. 346-351, 1988. 
[7] M. B. Rowan, J. I. Nicholls, and J. Steiner, "Torsional properties of stainless steel and nickel-titanium endodontic files," Journal of Endodontics, vol. 22, no. 7, pp. 341-345, 1996.

[8] A. Hieawy, M. Haapasalo, H. Zhou, Z.-j. Wang, and Y. Shen, "Phase transformation behavior and resistance to bending and cyclic fatigue of protaper gold and protaper universal instruments," Journal of Endodontics, vol. 41, no. 7, pp. 1134-1138, 2015.

[9] G. Çelik, F. Özdemir Kısacık, E. F. Yılmaz, A. Mersinlioğlu, İ. F. Ertuğrul, and H. Orhan, "A comparative study of root canal shaping using protaper universal and protaper next rotary files in preclinical dental education," PeerJ, vol. 7, Article ID e7419, 2019.

[10] N. Sheth, Y. Rathod, P. Shenoi, D. Shori, R. Khode, and A. Khadse, "Evaluation of new technique of sterilization using biological indicator," Journal of Conservative Dentistry, vol. 20, no. 5, pp. 346-350, 2017.

[11] A. C. D. Viana, B. M. Gonzalez, V. T. L. Buono, and M. G. A. Bahia, "Influence of sterilization on mechanical properties and fatigue resistance of nickel-titanium rotary endodontic instruments," International Endodontic Journal, vol. 39, no. 9, pp. 709-715, 2006.

[12] C. Valois, L. Silva, and R. Azevedo, "Multiple autoclave cycles affect the surface of rotary nickel-titanium files: an atomic force microscopy study," Journal of Endodontics, vol. 34, no. 7, pp. $859-862,2008$.

[13] S. Oh, K. Y. Kum, K. Cho et al., "Torsional and bending properties of $\mathrm{V}$ taper $2 \mathrm{H}$, ProTaper NEXT, NRT, and one shape," BioMed Research International, vol. 2019, Article ID 6368958, 2019.

[14] C. Canalda-Sahili, B. R. Au-Aguade, and J. Sentís-Vilalta, “The effect of sterilization on bending and torsional properties of K-files manufactured with different metallic alloys," International Endodontic Journal, vol. 31, pp. 48-52, 1998.

[15] C. Eggert, O. Peters, and F. Barbakow, "Wear of nickel-titanium lightspeed instruments evaluated by scanning electron microscopy," Journal of Endodontics, vol. 25, no. 7, pp. 494497, 1999.

[16] S. Alapati, W. Brantley, T. Svec, J. Powers, J. Nusstein, and G. Daehn, "SEM observations of nickel-titanium rotary endodontic instruments that fractured during clinical use," Journal of Endodontics, vol. 31, no. 1, pp. 40-43, 2005.

[17] M. Tanomaru-Filho, C. Galletti Espir, A. Carolina Venção, N. Macedo-Serrano, J. Camilo-Pinto, and J. GuerreiroTanomarua, "Cyclic fatigue resistance of heat-treated nickeltitanium instruments," Iranian Endodontic Journal, vol. 13, no. 3, pp. 312-317, 2018.

[18] G. Gambarini, G. Miccoli, M. Seracchiani, A. Morese et al., "Fatigue resistance of new and used nickel-titanium rotary instruments: a comparative study," Clinical Therapeutics, vol. 169, no. 3, pp. 96-101, 2018.

[19] S. A. Thompson, "An overview of nickel-titanium alloys used in dentistry," International Endodontic Journal, vol. 33, no. 4, pp. 297-310, 2000.

[20] Kreuzberg and $\mathrm{A}$. Yu, "Formation of nanostructures in combination of thermomechanical processing and control of functional characteristics of the alloys Ni-Ti shape memory," Abstract, p. 156, 2014.

[21] R. E. Smallman and A. H. W. Ngan, "Steel transformations," Modern Physical Metallurgy, pp. 473-498, 8th edition, 2014. 